\title{
Reform and Practice of the Trinity Teaching Mode for the Course Mechanical Control Engineering Base
}

\author{
Liping $\mathrm{Xu}^{1, \mathrm{a}}$, Haoyi $\mathrm{Ma}^{1, \mathrm{~b}}$, Jian $\mathrm{Li}^{1, \mathrm{c}}$ and Fengli $\mathrm{Li}^{1, \mathrm{~d}}$ \\ ${ }^{1}$ School of mechanical and electrical engineering, Henan University of Science and Technology, \\ Luoyang, 471003, China; \\ ${ }^{2}$ School of mechanical and electrical engineering, Henan University of Science and Technology, \\ Luoyang, 471003, China; \\ ${ }^{3}$ School of mechanical and electrical engineering, Henan University of Science and Technology, \\ Luoyang, 471003, China; \\ ${ }^{4}$ School of medical technology and Engineering, Henan University of Science and Technology, \\ Luoyang, 471003, China; \\ aemail:xlpzz@163.com, bemail:253279482@qq.com, cemail:ly-sword@163.com, \\ demail:1050674519@qq.com,
}

Keywords: reform in teaching; trinity; training mode; knowledge system; traditional education mode.

\begin{abstract}
Traditional training program, assessment requirements and evaluation criteria can already not meet the requirements of college students in the new era because of the characteristics of the Course Mechanical Engineering Control Base, the course is abstract, and subject is highly crossed. On the basis of the study of the current situation of college students, the characteristics of course, summary of the training program and the evaluation method of this course, a trinity training model combining closed-book exam, MATLAB computer examination, and after-school homework study is presented in this paper. This mode develops what is useful and discards what is not. It changes the way students learn this course from simple understanding to practice and then cognition, which plays a certain role in promoting students' learning enthusiasm, interest cultivation, application ability and the construction of knowledge system.
\end{abstract}

\section{Introduction}

The course Mechanical Engineering Control Base is an important professional basic course of mechanical specialty. It is the product of mutual penetration of many disciplines, such as automatic control, electronic technology, and computer science and so on. Compared with the traditional mechanical courses, this course has the characteristics of large computational complexity, abstract and multidisciplinary cross, etc. Because of these characteristics, students have to understand the "Forward looking and Retrospection" in the learning process. The so-called "Forward looking" refers to the process of learning this course have to be able to continue to review what they have learned before. Because the course in the analysis process may use a lot of knowledge learned before. The so-called "Retrospection" refers to the disciplines of knowledge and ideas can be applied to the future of professional[1].

However, most of the students do not pay more attention to the course, through the survey of the major colleges and universities. Some of them regard this course as a "Math" lesson and few people know how to use the subject to solve practical engineering problems as well as how to combine this subject with other knowledge. Regarding the course as an isolated subject. Such wrong cognition will produce adverse effects on the cultivation of interest and the degree of attention, then will make the mechanical professional students appear professional "out of touch" phenomenon. It is not conducive to the establishment of a complete knowledge system for mechanical professional students[2]. Even worse, it will have a lot of adverse effects on the development of students in the future.

Through the investigation of contemporary college students' learning situation, the Mechanical Engineering Control Base course characteristics analysis and the requirements of engineering 
practical on the subject, we are putting forward "Trinity" teaching reform scheme: closed book examination, MATLAB computer operating examination and after-school homework study. It is a new attempt to reform the traditional teaching mode.

\section{Investigation on the Learning Situation of the Course Mechanical Engineering Control Base}

In May 2016, a survey was carried out based on 321 students with good grades of the course in seven universities. The examination content mainly includes two items: Using computer simulation with MATLAB and solving the problem of simple mechanical transmission in the course of mechanical control engineering. Statistical results are shown in Fig.1.

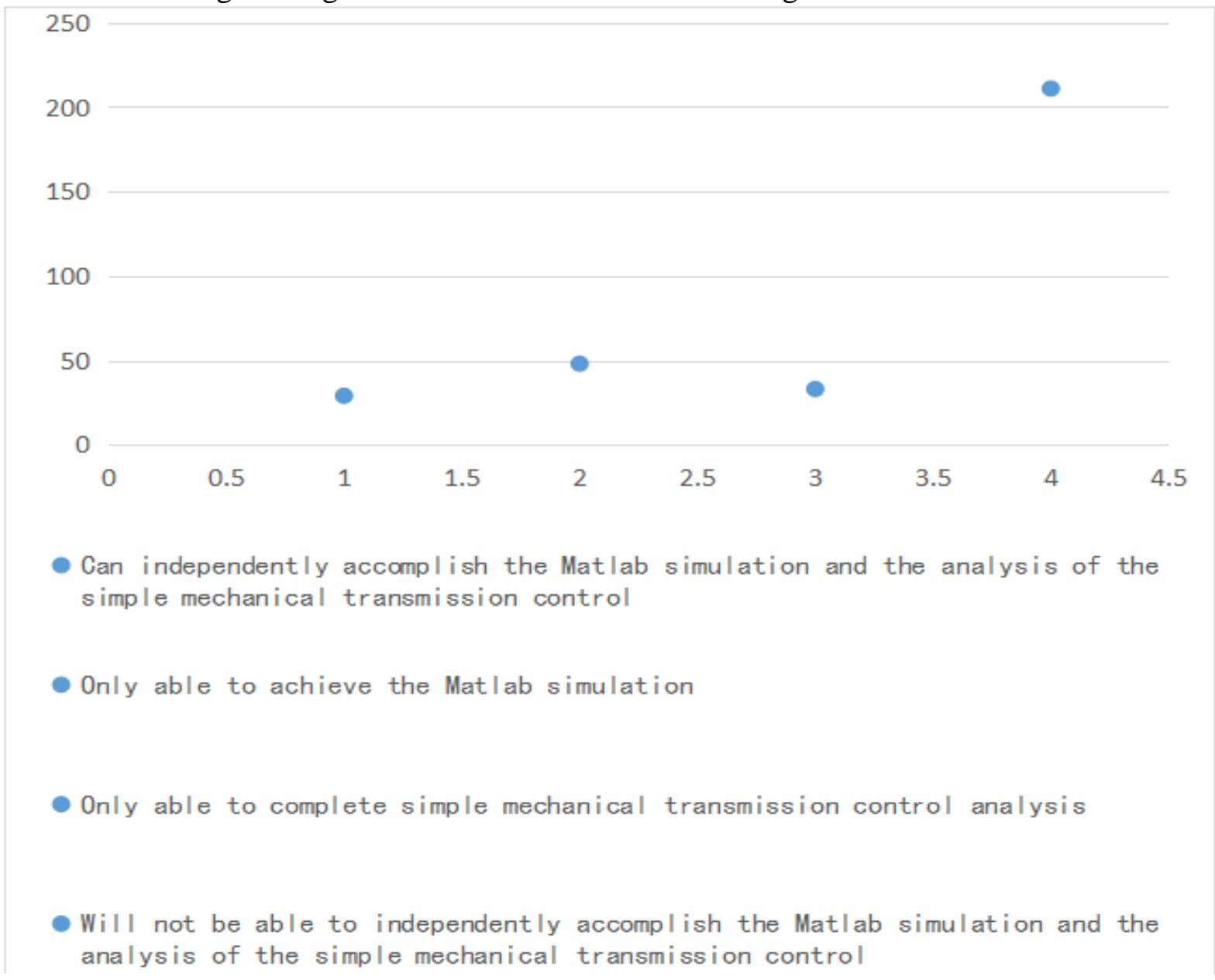

Fig. 1 The 2013 level Mechanical Engineering Control Base test summary

It can be concluded from the above results: test scores and engineering practice ability have big difference, excellent course grade students engineering practice ability is still very weak and only about $9 \%$ of the students have the ability to solve simple practical engineering problems independently. What's more, by the investigation we also find most school pay more attention to the textbooks in teaching and the closed book examination, while the MATLAB simulation often as a self-study content or simply presented in class and teachers often do not put forward higher requirements.

\section{The Analysis on the Characteristics of the Course Mechanical Engineering Control Base}

The course Mechanical Engineering Control Base has different characteristics from other mechanical discipline. Tab.1 is compared the Mechanical Engineering Control Base with other mechanical discipline. Analysis on the characteristics of the course. 
Table1 The characteristics of the Course Mechanical Engineering Control Base compared with other major courses

\begin{tabular}{|c|c|c|c|}
\hline $\begin{array}{c}\text { Course name } \\
\text { Course characteristics }\end{array}$ & $\begin{array}{l}\text { mechanical design } \\
\text { basis }\end{array}$ & $\begin{array}{l}\text { Control Engineering } \\
\text { Foundation }\end{array}$ & $\begin{array}{l}\text { Electrical control } \\
\text { and PLC }\end{array}$ \\
\hline $\begin{array}{l}\text { Degree of } \\
\text { intersection }\end{array}$ & Higher & High & Higher \\
\hline Subject abstract degree & Lower & High & Higher \\
\hline Main application fields & Mechanical field & $\begin{array}{l}\text { Various fields of } \\
\text { industrial control }\end{array}$ & $\begin{array}{l}\text { Electrical control } \\
\text { field }\end{array}$ \\
\hline $\begin{array}{l}\text { Relationship with other } \\
\text { disciplines }\end{array}$ & $\begin{array}{l}\text { The basic course of } \\
\text { mechanical } \\
\text { engineering }\end{array}$ & $\begin{array}{c}\text { The transition course to } \\
\text { undertake professional } \\
\text { basic course and } \\
\text { specialized course }\end{array}$ & $\begin{array}{c}\text { Specialized courses } \\
\text { in mechanical and } \\
\text { electrical control }\end{array}$ \\
\hline
\end{tabular}

The conclusion can be drawn from Table 1: compared with the traditional mechanical course, The course Mechanical Engineering Control Base has the high degree of intersection and wide application range. What's more, it is a bridge of communication between professional basic course and specialized course. Because of the above characteristics, the course in the training mode should be different from other disciplines and this approach can help students to absorb and master the subject, so as to achieve the purpose of learning.

\section{The Improvement Measures for the Training Scheme of the Course Mechanical Engineering Control Base}

On the basis of above research results, we should pay more attention to the situation and put forward the corresponding measures. Specific measures are changing the original simple classroom learning and closed book exam into the combination of the closed book examination, examination on MATLAB and after-school big homework evaluation, which can both examine students' basic knowledge and the ability to exercise students' engineering practical application[3,6]. The "trinity" training mode flow diagram are shown in Fig.2, ordinary teaching training mode are shown in Fig.3. By contrast, the training mode of "trinity" is more complete and more conducive for students on the subject of study.

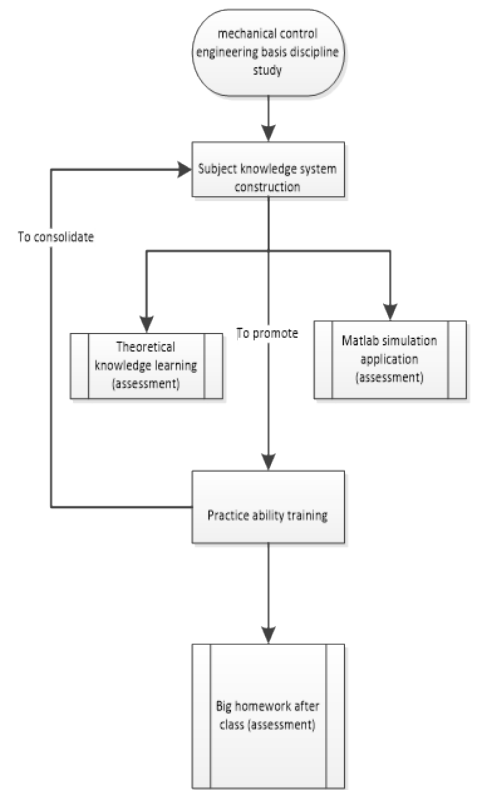

Fig .2 Trinity teaching mode flow chart

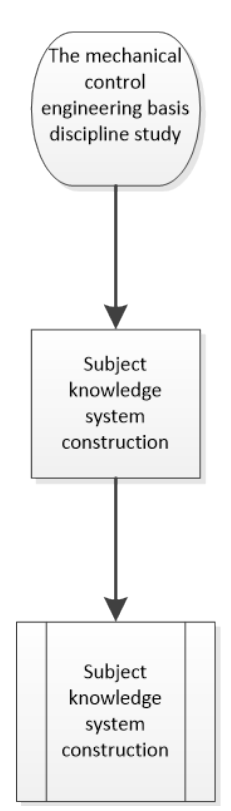

Fig .3 Flow chart of traditional teaching mood 


\subsection{Closed Book Exam Reform and Innovation}

Closed book examination is the traditional examination method of most colleges and universities taken. In a sense, the closed book examinations play an irreplaceable role in investigating students' basic knowledge and supervise students' learning. However, due to the closed book examination is requiring students to finish a certain amount of study content in unit time, which is very one-sided for students. It is not difficult to see that the main role of the closed book examinations is to check students' learning achievements. But as a test of ability is obviously inadequate, especially for the course, only the closed book examination for the cultivation of application student's ability is not up to the assessment requirements. Therefore, we also need other auxiliary examination methods to improve students' knowledgeable level, except for the closed book examination. And these methods can lay a solid foundation for future engineering practice,

\subsection{The Cultivation of the Computer Simulation Based on MATLAB}

MATLAB is large mathematical calculation software developed by the American Mathworks company and it has been widely used in the field of control. The MATLAB simulation technology in the application of control should be pay more attention, and we should attach great importance to this skill[4]. It will bring great convenience to the practical project, for example: drawing the open-loop transfer function for:

$$
G(s) H(s)=\frac{4}{\left(5 s^{2}+2 s+1\right)(20 s+1)}
$$

The Nyquist diagram of the system is as formula (1). Using the traditional way to paint, it involves a huge extra work and the accuracy of the drawing is not high. By contrast, drawn by MATLAB simulation software can greatly shorten the calculating work. Running the program as follows:

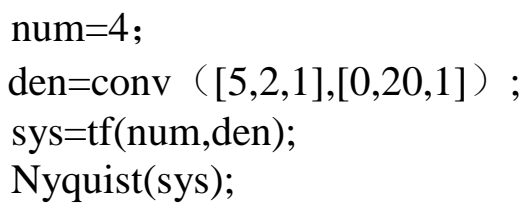

What can be seen from above is that using MATLAB simulation software to draw Nyquist diagram just need four steps programs, whether in the reduction of workload or the accuracy of drawing is much better than before. By learning the skills will make the abstract course become more concrete. The Nyquist diagram based on the MATLAB system is shown in Fig.4:

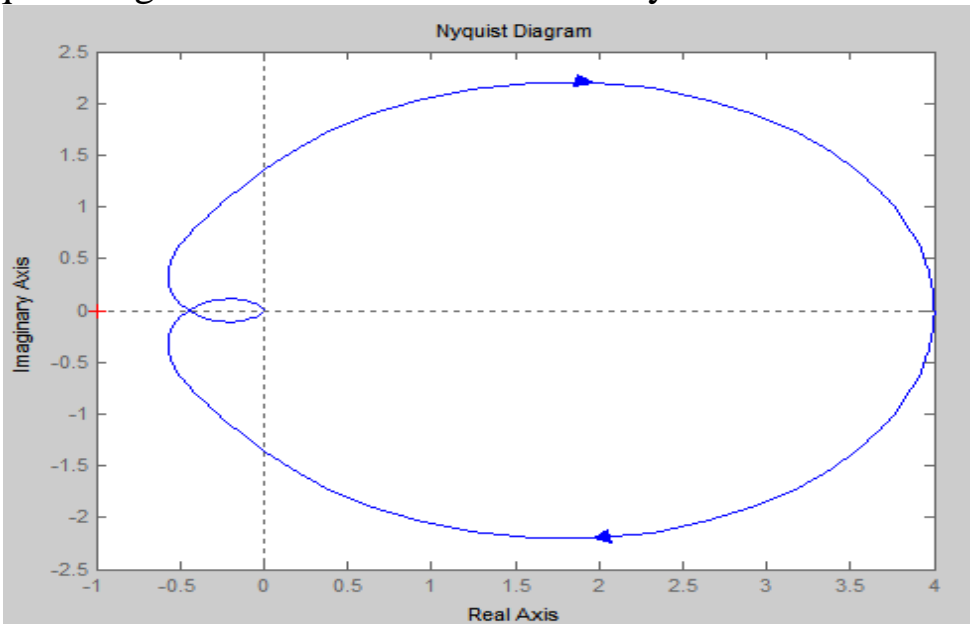

Fig .4 the Nyquist diagram of system based on MATLAB

Because the course Mechanical Engineering Control Base have the features of abstract and theoretical. In practice, it does not have material object for reference. Therefore, MATLAB simulation, as a practical learning outside the theoretical study, plays an important role in the improvement of students' extracurricular ability. The computer simulation software of learning will bring a lot of benefits. On the one hand, it can change the abstract writing study into a specific union of number and shape, which can help to cultivate students' interest in the subject. On the other hand, the MATLAB simulation software can deepen students understanding of the content 
$[5,6]$.

\subsection{Increase Big Homework Assessment Link after Class}

Each chapter of the control engineering Foundation contacts closely. The introduction, Laplace transform, transfer function and time response analysis, error analysis, frequency analysis, stability analysis and system calibration are a whole, each section is linked closely. But we often find many people who neither understand the connection between chapters nor the connection between this course and the other disciplines, which lead to a lot of people don't know how to use what they have learned to solve problems in engineering practice. Thus, the link of after-school homework is a good method for the ability of students' training. On the one hand, students can continue to review prior knowledge. On the other hand, the big homework after class can improve students' ability to solve practical problems.

The selected topic of big homework after class is particularly wide, which can choose the hydraulic servo system, industrial robot position control analysis and other mechanical or electrical integration of control systems. In hydraulic servo system, for example, in the analysis of a practical problem, lots of knowledge can be used for hydraulic servo system analysis, such as the force analysis of valve body, the deduction of transfer function, the establishment of differential equation, the establishment and simplification of block diagram, the drawing of Bode chart, the analysis of system stability and the influence of various parameters on the stability and the analysis of steady state error, the design of the system calibration, etc.[7].

\section{Trinity Teaching Reform Questionnaire Survey}

Recently, our school holds a "Trinity" teaching reform forum, the meeting invited teachers, students and representatives more than 60 people. According to statistics, about $73 \%$ of the students, $71 \%$ of the teachers and $79 \%$ enterprise leadership support of the "trinity" of Mechanical Engineering Control Base teaching mode reform, part of students, teachers and enterprise representatives also express their views on the question. Up to now, some colleges and universities have adopted "Trinity" of the reform program.

\section{Conclusion}

In a new round of teaching reform, Mechanical Engineering Control Base is to analysis the causes of above phenomenon and conscientiously summarize, putting forward a kind of suitable for contemporary college students' education of models[7]. Compared with the traditional education: the "trinity" teaching mode has above following features:

(1) The "trinity" teaching mode change the traditional single training mode, "Trinity" training mode has diversity, which help to improve students' learning enthusiasm.

(2) The "trinity" cultivation model by computer simulation and practical application problem can make boring course become vivid, which can help students to cultivate their interest in learning.

(3) The "trinity" training mode on the basis of the theory can pay more attention to the cultivation of students' practical application ability.

(4) Training mode of the "trinity" has the purpose of building "theory to guide practice, practice to consolidate theory" learning process and it is more conducive to the establishment of knowledge system for students[8].

\section{Acknowledgment}

The authors gratefully acknowledge the superior course of HAUST for financial support of this research work.

\section{References}

[1]. M.Jianxi Yang, Liping Xu. Foundation of Control Engineering. Beijing: Science Press, 2008. 
[2]. J.Zhongyan Ruan,Jinwei Fan, Hui Liu. Mechanical Engineering Control Base courses active learning teaching strategy research. The Chinese modern education equipment, vol 17, 2014, pp.48-55.

[3]. J.Lianjin Li. Mechanical control engineering teaching reform. Professional curriculum construction, vol 2, 2016, pp.59-60.

[4]. J.Wei Wang, Aiming Shen, Shunying Lin, Ya Chen, Dianjun Wang. Application of MATLAB in the Control Engineering Course. Journal of Anhui Normal University(Natural Science Edition), vol.34 No.2 Mar.2011, pp.142-144.

[5]. J.Shaojun Zhao.Concept clear and interactive mechanism-the current teaching reform in the new curriculum and class relations. Journal of Educational Science of Hunan Normal University, vol 15, No .1 Jan., 2016, pp..52-59..

[6]. M.Chunxing Wang. The hydraulic control system. Beijing: Beijing industry press, 2012.

[7]. J.Honglian Zhang.Mechanical engineering research "control engineering foundation" teaching. China power education, vol 10, 2013, pp.90-91.

[8]. J.Nianjin Ding. Teaching system reconstruction: a necessity. Journal of hunan normal university education sciences, vol 1, 2015, pp.51-57. 